condition initially, but 12 hours later she became comatose with a large pontine and midbrain hemorrhage. Both patients expired.

Conclusion Because all other causes seemed implausible, we concluded that both patients died of brainstem reperfusion injury. Because of the improved ability to treat vertebrobasilar occlusive disease, reperfusion injury in the posterior circulation may be increasingly recognized and characterized.

Disclosures T. Higashimori: None. J. Kim: None. D. Sandhu: None. C. Streib: None. R. Tummala: None.

\section{E-007 RESULT OF STENT-ANGIOPLASTY WITH WINGSPAN STENT FOR SYMPTOMATIC INTRACRANIAL STENOSIS}

S You. Neurosurgery, University of Ulsan College of Medicine, Gangneung Asan Hospital, Gangneung-si, Republuic of Korea

\subsection{6/neurintsurg-2016-012589.79}

Purpose The purpose of this study is to investigate the treatment results, and procedure-related complications of stentangioplasty for symptomatic intracranial arterial stenosis with Wingspan stent and Gateway balloon.

Materials and methods From May. 2010 to May 2015, 76 patients (52 males, 24 females, mean age: $66.6 \pm 8.9$ years) with symptomatic intracranial arterial stenosis were treated. Inclusion criteria are acute and/or subacute symptomatic infarction or repeated transient ischemic attack (TIA) (infarction vs. TIA: 39 vs. 37) and severe stenosis related to symptoms confirmed with catheter angiography. The numbers of stenotic lesions were 29 cases on ICA, 34 on MCA, and 13 on vertebrobasilar (V-B) artery. All of the used stents for treatment were Wingspan self-expanding stent and Gateway balloon. Mean NIHSS at admission was $1.4 \pm 1.9$, and mean stenosis rate was $76.8 \pm 6.2 \%$. Clinical status (including NIHSS) and angiographic results were assessed retrospectively. Results Stents were successfully deployed at first trial in almost all cases except only two cases due to tortuous ICA course $(97.4 \%)$, and in one case successful stenting was done at second trial (98.7\%). Periprocedural complications occurred in 11 cases (14.5\%), and symptomatic cases were only $6(7.9 \%$, transient vs. permanent: $4(5.3 \%$ vs. $2.6 \%)$. Of 76 cases 67 were followed clinically over 6 months $(88.2 \%)$ and the mean follow-up period was $25.8 \pm 20.0$ months). Angiographic follow-up was performed in 57 cases $(75.0 \%$. $13.9 \pm 11.8$ months). The mean NIHSS after stent-angioplasty was $0.8 \pm 1.7$ and $0.5 \pm 1.7$ at last clinical follow-up day. Poststenting residual stenosis was $8.7 \pm 13.0 \%$, and $14.8 \pm 25.3 \%$ at last angiographic follow up. In-stent restenosis over $50 \%$ occurred in 7 cases $(7 / 57,12.3 \%)$, and 6 cases were retreated successfully with Gateway balloon (3) or Drugeluting balloon (3). Symptomatic infarctions were occurred in 4 of $76(5.3 \%)$ patients during the clinical follow-up period. Conclusion Stent-angioplasty with Wingspan self-expanding stent appeared to be safe and effective for intracranial arterial stenotic disease. However, it should prompt more strict selection criteria and desperate angiographic follow-up for better clinical results.

Disclosures S. You: None.

\section{PATIENT OUTCOMES FOLLOWING TREATMENT OF HIGH FLOW VASCULAR LESIONS OF THE ANTERIOR CRANIAL FOSSA AND ORBIT}

${ }^{1} \mathrm{~A}$ Moraff, ${ }^{1} \mathrm{R}$ Dodd, ${ }^{2} \mathrm{M}$ Marks, ${ }^{2} \mathrm{H}$ Do, ${ }^{1} \mathrm{G}$ Steinberg, ${ }^{1} \mathrm{~S}$ Chang, ${ }^{2} \mathrm{~J}$ Heit. ${ }^{1}$ Neurosurgery, Stanford University, Stanford, $C A$; ${ }^{2}$ Interventional Neuroradiology, Stanford University, Stanford, CA

\subsection{6/neurintsurg-2016-012589.80}

Introduction High flow vascular lesions of the anterior cranial fossa and orbit (HFVL) include arteriovenous malformations and dural arteriovenous fistulae located within the orbit, periorbital region, ethmoid sinuses, the anteroinferior frontal lobes, or within the dura of the anterior cranial fossa. Rupture of HFVL may result in intracranial hemorrhage, so these lesions typically undergo treatment even when discovered for other reasons. HFVL may be treated by trans-arterial endovascular embolization, surgical ligation, radiosurgery, or a combination of these approaches, but the most optimal treatment is not well defined. We determined patient outcomes and HFVL obliteration after treatment.

Methods We retrospectively reviewed all patients referred for diagnostic angiography or endovascular embolization of HFVL at our neurovascular referral center over an 8 year period. Patient demographic, treatment, and outcome data were deterred from the medical record. DSA, CT, and MRI studies were reviewed for HFVL characteristics and obliteration after treatment.

Results HFVL were identified in 11 patients (five females and six males) ranging in age from 8 to 76 years (mean 53 years). Presenting symptoms included headaches (nine patients; 82\%), visual symptoms (five patients; 45\%), intracranial hemorrhage (two patients; 18\%), tinnitus (one patient; 9\%), or no symptoms (one patient; 9\%). Nine patients (81\%) had medical comorbidities, but none had a hypercoagulable disorder or prior trauma. The HFVL were comprised of seven dural arteriovenous fistulae (64\%) and four arteriovenous malformations (36\%). The ophthalmic artery was the dominant feeding vessel in 10 patients (91\%). 10 patients (91\%) were treated, including embolization via the ophthalmic artery (four patients; $36 \%$ ), embolization followed by surgical ligation (3 patients; $27 \%$ ), embolization followed by radiosurgery (one patient; 9\%), surgical ligation alone (one patient; 9\%), or radiosurgery alone (one patient; 9\%). Endovascular embolization was performed with Onyx (six patients; 75\%) or n-BCA (two patients; 25\%) HFVL cure was achieved in six patients $(55 \%)$, including three patients treated by embolization alone, two treated by embolization and surgical ligation, and one by surgery alone. One patient treated by embolization alone developed a post-treatment partial visual deficit, but there were no other complications related to treatment. No patient deaths occurred.

Conclusions HFVL are uncommon lesions that are challenging to treat. Endovascular embolization alone or in combination with surgery results in HFVL obliteration in $50 \%$ of patients with an acceptable safety profile. Further studies should determine whether radiosurgery alone or in combination with endovascular embolization results in high rates of HFVL cure. Disclosures A. Moraff: None. R. Dodd: None. M. Marks: None. H. Do: None. G. Steinberg: None. S. Chang: None. J. Heit: None. 